\title{
The evolution of ornithischian quadrupedality
}

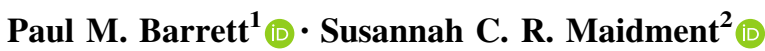

Received: 27 February 2017/ Accepted: 16 June 2017/Published online: 12 October 2017

(C) The Author(s) 2017. This article is published with open access at Springerlink.com

\begin{abstract}
Ornithischian dinosaurs were primitively bipedal, but reverted to quadrupedality on at least three (and potentially several more) occasions: in Ceratopsia, Thyreophora and Hadrosauriformes. Each of these reversals was accompanied by anatomical changes to the whole skeleton that enabled the forelimb to function in weight bearing and that also resulted in numerous changes to the hip and hind limb musculature. Each quadrupedal clade acquired a suite of similar biomechanical characters, although they varied in terms of function and in how these character complexes were assembled. Some similar changes occurred in parallel among sauropodomorph dinosaurs as they transitioned from bipedality to quadrupedality. It is unclear why bipedal ornithischians reverted to quadrupedalism, but neither increases in body size nor the acquisition of dermal armour seem to have played a significant role. Increased head size might have influenced the position of the centre of mass and stance in ceratopsians and it is plausible that the evolution of herbivory played an important role in both ornithischians and sauropods, but the latter hypothesis is difficult to test.
\end{abstract}

Keywords Ornithischia · Dinosauria · Locomotion · Quadrupedality · Biomechanics · Functional morphology · Evolution

The original version of this article was revised due to a retrospective Open Access order.

Paul M. Barrett

p.barrett@nhm.ac.uk

1 Department of Earth Sciences, Natural History Museum, Cromwell Road, London SW7 5BD, UK

2 School of Environment and Technology, University of Brighton, Lewes Road, Brighton BN2 4GJ, UK
Resumen Los dinosaurios Ornitísquios, bípedos en origen, revertieron a la condición cuadrúpeda en al menos tres (y potencialmente más) ocasiones: en Ceratopsia, Thyreophora y Hadrosauriformes. Cada una de estas reversiones vino acompañada de cambios anatómicos en el resto de esqueleto que permitieron a la extremidad anterior funcionar para soportar su peso y llevaron a cambios en la cadera y la musculatura dela extremidad posterior. Cada clado cuadrúpedo adquirió una serie de caracteres biomecánicos parecidos, aunque variaron en su función y en la manera en la que estos conjuntos de caracteres encajaban. Cambios parecidos aparecieron paralelamente entre los dinosaurios sauropodomorfos durante su transición de bípedos a cuadrúpedos. Aunque no queda claro por qué los ornitísquios revertieron al cuadrupedismo, ni el aumento de masa corporal ni la adquisición de armadura parecen haber jugado un papel significativo. Un mayor tamaño de la cabeza pudo haber repercutido en el cambio de posición del centro de masas y cambio en la postura en los ceratopsios, y es posible que la evolución de la fitofagia jugara un papel importante, tanto en ornitísquios como saurópodos, aunque sea una hipótesis difícilmente contrastable.

Palabras clave Ornithischia · Dinosauria · Locomoción · Cuadrupedismo · Biomecánica · Morfología funcional . Evolución

\section{Introduction}

The majority of tetrapods, both living and extinct, are quadrupedal and this locomotor mode represents the primitive condition for fully terrestrial members of the clade. Bipedalism has evolved from quadrupedal ancestors in several tetrapod lineages independently, but transitions 
to bipedality are relatively rare although phylogenetically widespread, with examples among marsupials, rodents (in saltators in both of the latter cases), afrotherians (pangolins), hominids, squamates (though on a facultative basis) and pseudosuchian archosaurs (e.g. poposauroids). However, in terms of abundance and taxic-richness, the most successful clade of bipeds is Dinosauria (inclusive of birds), which encompasses $c$. 11,000 living species as well as their extinct relatives. The earliest-known members of all main dinosaur lineages (Ornithischia, Sauropodomorpha and Theropoda) are bipedal, as are the majority of dinosaur outgroups (including lagosuchids and pterosaurs), indicating that this stance is primitive for the clade (e.g. Sereno 1997). The advent of dinosaur bipedality could be viewed as one of the adaptations underpinning dinosaur success, as it enabled dinosaurs to attain greater stride lengths and speeds than quadrupedal reptiles (e.g. Alexander 1976). Moreover, the anatomical modifications associated with bipedalism and an upright stance also permitted more efficient body support, facilitating the later evolution of gigantism in some lineages (e.g. Sander et al. 2011)

Paradoxically, although bipedalism characterises all theropods, many extinct, non-avian dinosaur lineages abandoned this stance, reverting to quadrupedality. This occurred independently on at least four (and potentially more) occasions, at least once in Sauropodomorpha and a minimum of three times in Ornithischia (in Thyreophora, Ceratopsia and Hadrosauriformes) (Sereno 1997; Maidment and Barrett 2012). In two cases (Sauropodomorpha and Thyreophora), these reversions occurred early in dinosaur history only $\sim 15-20 \mathrm{Ma}$ after the origin of Dinosauria, sauropodomorphs being the first to adopt secondary quadrupedalism, in the Late Triassic to Early Jurassic (e.g. Yates and Kitching 2003; Bonnan and Yates 2007; Yates et al. 2010), while the first quadrupedal thyreophoran is known from the basal Jurassic (Owen 1861). The other two reversions, in Ceratopsia and Hadrosauriformes, happened much later in time, during the late Early to early Late Cretaceous (Sereno 1999; Weishampel et al. 2004). Another possible independent reversion also occurred in rhabdodontid ornithopods, although the time that this occurred is unclear due to the extensive ghost lineage separating this clade from other ornithopods (Weishampel et al. 2003; Maidment and Barrett 2014). It is also possible that the nearest outgroup to Dinosauria, Silesauridae, reverted to quadrupedalism from a bipedal ancestry sometime during the Middle Triassic, but a lack of articulated material makes this claim harder to assess (Langer et al. 2013). It is potentially noteworthy that reversions from bipedality to quadrupedality are known only in dinosauriformes, although the macroevolutionary significance of this observation is currently unknown: by contrast, members of all other tetrapod groups that attained a bipedal stance retained this ability.

Although dinosaur locomotion has been the topic of extensive research, with osteological, myological, biomechanical and ichnological lines of evidence being used to reconstruct speed, stance and gait (e.g. Coombs 1978; Thulborn 1982, 1989; Alexander 1985; Gatesy 1990; Carrano 1998, 2001, 2005; Gatesy et al. 1999; Hutchinson and Garcia 2002; Sellars and Manning 2007; Sellars et al. 2009; and many others), relatively few authors have speculated on why bipedal dinosaurs, having acquired numerous specialisations to enable this ability, should revert to quadrupedalism. Previous suggestions have included increased body size, the development of elaborate dermal armour, the acquisition of an elongate gut and changes in relative head size (e.g. Colbert 1981; Norman and Weishampel 1991; Sereno 1997; Lockley 2007; Sereno et al. 2007), but few of these studies considered the problem within a phylogenetic context, nor did they attempt to test these suggestions biomechanically.

Here, we summarise recent work on ornithischian quadrupedality, outlining the anatomical and functional changes involved in the transition from bipedality, placing these changes within a comparative evolutionary context and reviewing biomechanical modelling approaches that have been applied to test both biomechanical and evolutionary hypotheses. This involves positing two separate questions: how did ornithischians revert to quadrupedality? and why did they do so?

\section{Determining stance in ornithischians}

Historically, ornithischian stance (and that in other nonavian dinosaurs) has been extrapolated from a variety of qualitative and quantitative observations that include overall build, orientation of the vertebral column, presumed locomotor capabilities, body size, differences in the proportions of the neck, trunk, tail and limbs, and considerations over hand function (e.g. Galton 1970; Coombs 1978; Norman 1980; Dilkes 2001; and many others). Based on comparisons with extant taxa (primarily mammals), quadrupedal non-avian dinosaurs were generally thought to have the following features, which are usually the converse of those found in bipeds: forelimbs that are relatively long in comparison to hind limb length (so that all four limbs function in weight support); trunks that are elongate relative to hind limb length (implying an anteriorly positioned centre of mass); tails that are relatively short in comparison with trunk length (as they are not required as a counterbalance); a vertebral column that is oriented horizontally, rather than tilted upwards (again, implying an anterior shift in the centre of mass); zeugopodia and metapodia that are 
short with respect to the stylopodia in both fore- and hind limbs; and hands that are broad and adapted for weightbearing, ending in hoof-shaped rather than claw-like unguals (e.g. Colbert 1964; Galton 1970; Thulborn 1977; Coombs 1978; Norman 1980; Carrano 2005). Application of these generalised rules led to a consensus that ankylosaurs, ceratopsids and stegosaurs were obligate quadrupeds, while heterodontosaurids, some other early diverging taxa (e.g. Lesothosaurus, Scutellosaurus), pachycephalosaurs, non-neoceratopsian ceratopsians (e.g. Psittacosaurus) and non-iguanodontian ornithopods were bipedal (e.g. Sereno 1997, 1999; Weishampel et al. 2004). However, mosaic distributions of these features in other taxa has led to controversy over stance in several groups, primarily in hadrosaurids and other iguanodontian ornithopods (e.g. Galton 1970; Norman 1980; Dilkes 2001; Carpenter and Wilson 2008), but also in Scelidosaurus (Thulborn 1977) and some ceratopsians (Senter 2007; Maidment and Barrett 2014). Moreover, ontogenetic shifts in stance have been posited for some ornithopod taxa (e.g. Iguanodon, Maiasaura) and Scelidosaurus, with juveniles interpreted as bipeds and adults as quadrupeds (Norman 1980; Dilkes 2001; Maidment and Barrett 2014); a converse quadrupedal to bipedal shift has been proposed for the ceratopsian Psittacosaurus (Zhao et al. 2013).

Re-assessment of osteological indicators traditionally associated with quadrupedality, conducted by comparing the phylogenetic distributions of these characters among taxa that are considered to be uncontroversially quadrupedal or bipedal (e.g. ankylosaurs and basal ornithopods, respectively), has revealed that many of these features are of limited use in determining stance (Maidment and Barrett 2014). For example, tail to trunk length ratios (Galton 1970) cannot be assessed in many controversial taxa due to the relative rarity of complete dinosaur tails (see Hone 2012) and a proposed link between scapulocoracoid coossification and quadrupedality (Norman 1986) is probably the result of ontogeny rather than function (Maidment and Barrett 2014). The proposal that quadrupeds have relatively shorter hands compared to bipeds (Colbert 1964; Galton 1970) is undermined by the observation that quadrupedal ankylosaurs and ceratopsians have metacarpal 3 length/ radius + humerus lengths similar to those of undoubted bipeds (Maidment and Barrett 2014). Similarly, it has been proposed that radius/humerus length ratios were lower in quadrupeds (Galton 1970), but these differences are marginal with extensive overlap in this ratio between quadrupedal and bipedal taxa (Maidment and Barrett 2014). Some features that have been proposed to characterise quadrupedality in sauropodomorphs, such as the presence of a facet on the distal radius for reception of the ulna (Yates and Kitching 2003), are present in a wide range of both quadrupedal and bipedal ornithischians and may not be of help in determining stance outside of Sauropodomorpha.

Nevertheless, several features do appear to be strongly correlated with quadrupedal stance, including: the presence of an anterolateral process on the ulna (Bonnan 2003; Yates and Kitching 2003; Yates et al. 2010); hoof-like manual ungual phalanges (e.g. Galton 1970; Norman 1980); a femur that is longer than the tibia (Colbert 1964; Galton 1970); a femur that is straight in lateral view (Yates and Kitching 2003; Chinnery 2004); a pes that is relatively shorter relative to tibia + femur length (Colbert 1964; Galton 1970; Yates and Kitching 2003) [although both of the latter features could be related to increased body size (Maidment and Barrett 2014)]; reduction of the fourth trochanter (Galton 1970; Yates and Kitching 2003); a transversely expanded iliac blade (Carrano 2005; Maidment and Barrett 2014); and higher forelimb/hind limb length ratios than those in bipeds (Galton 1970), although the utility of this feature is somewhat equivocal (Maidment and Barrett 2014). The biomechanical significance of some of these characters remains untested: for example, it is unclear what functional changes result from reduction of the fourth trochanter. However, in other cases a clearer link is present: for example, the anterolateral process of the ulna is related to medial migration of the radius and pronation of the manus, enabling a weight-bearing function for the forelimb (Bonnan 2003). Similarly, hoof-like manual unguals are also involved in weight bearing (e.g. Norman 1980) and the lateral expansion of the ilium is associated with reorganisation of the hip musculature, which enables increased abduction moment arms that are required for limb stabilisation (Maidment et al. 2014a; see below).

Using these osteological indicators of quadrupedality allows the stance of other controversial taxa to be assessed more rigorously. Hadrosaurids and many other hadrosauriforms have all of the proposed correlates of quadrupedality, strongly supporting the idea that they were habitually quadrupedal. Some of these features are also present in the non-hadrosauriform ornithopods Tenontosaurus, Uteosaurus and Zalmoxes, suggesting that these taxa might have been quadrupeds, or at least facultatively quadrupedal, and that this ability might have evolved on several occasions in Ornithopoda (Maidment and Barrett 2014). Scelidosaurus also possesses some features indicative of quadrupedality (e.g. a transversely expanded ilium); conversely, some non-ceratopsid ceratopsians, such as Leptoceratops, lack many of these features and are more similar to bipedal taxa in most respects (Maidment and Barrett 2014). Indeed, the only 'definitive' quadrupedal character present in Leptoceratops is the presence of hoofshaped manual unguals. Optimising the distribution of these characters on to ornithischian phylogeny reveals that each major lineage acquired 'quadrupedal' features in 
different orders, indicating a lack of tight functional linkages between them. It also emphasizes the distinct convergent pathways that each quadrupedal clade followed to reach this condition, especially among ornithopods, among which a pattern of mosaic character evolution occurs indicating numerous experiments seeking solutions to the problems posed by quadrupedality (Maidment and Barrett 2012, 2014).

Ontogenetic shifts in posture have been proposed on the basis of intraspecific changes in some of the aforementioned functional characters. The quadrupedal to bipedal shift inferred for Psittacosaurus is predicated upon the differential allometry of the fore- and hind limbs, which results in forelimbs that are relatively longer in young juveniles and shorter in older juveniles and adults (Zhao et al. 2013). A similar phenomenon has also been documented in a growth series of the sauropodomorph Massospondylus (Reisz et al. 2005). However, although there is evidence to link differing fore- and hind limb proportions to stance (Galton 1970: Maidment and Barrett 2014), Psittacosaurus possesses no unambiguous osteological indictors of quadrupedality at any age-for example, the manus lacks hoof-like unguals and is held in a supinated pose, so it appears to have been unsuitable for weightbearing at any age (Senter 2007). Additional evidence is required to test this ontogenetic shift. Conversely, bipedal to quadrupedal changes in ornithopod stance are also based on differential allometry, with increases in relative forelimb length, robustness and the size of humeral muscle attachments occurring through ontogeny (Norman 1980; Dilkes 2001). In these cases unambiguous correlates of (at least facultative) quadrupedality, which do not exclude juvenile bipedality, are present throughout life (e.g. hoofshaped unguals).

Trackways provide direct data on stance, but differences in their preservation and formation can provide conflicting information. Historically, numerous trackways composed of large-sized, three-toed, blunt-hooved footprints, lacking associated handprints, were assigned to Ornithopoda and provided a major source of evidence favouring bipedal locomotion in iguanodontians (e.g. Lockley 1991). However, other trackways showing clear manus impressions and documenting quadrupedal locomotion are also known, for both non-hadrosaurid iguanodontians and hadrosaurids (Lockley and Wright 2001). Conversely, trackways attributed to small ornithopods (e.g. Dinehichnus) consistently lack manus impressions (Lockley and Wright 2001). Computer modelling of trackmaker/substrate interactions suggests that the absence of manus impressions from large 'bipedal' ornithopod trackways might result from differential loading, whereby the forelimb supports a smaller proportion of the total body mass than the hind limb: consequently, the manus indents the sediment less frequently and/or less conspicuously than the pes (Falkingham et al. 2011). This suggestion is supported by tracksites preserving both pes-only and manus-pes ornithopod trackways, with this differential preservation reflecting the mechanical properties of the sediment, rather than representing genuine locomotor differences (Castanera et al. 2013). As a result, trackway evidence now complements the osteological evidence in suggesting that large-bodied ornithopods were quadrupedal, while smallbodied taxa were bipeds. A variety of other quadrupedal ornithischian trackways are also known, whose combination of manus and pes morphology indicate referral to either thyreophorans or ceratopsids (e.g. Lockley and Hunt 1995; McCrea et al. 2001).

\section{Functional anatomy and biomechanics}

A suite of convergent osteological changes that occurred during the evolution of the three ornithischian clades that evolved quadrupedality can be correlated with concurrent changes in the arrangement of limb musculature in both the fore- and hind limbs (Maidment and Barrett 2012). These changes can be related to muscle function and stance, and provide information on the modifications required to the musculoskeletal system that were essential for quadrupedality to evolve (Maidment et al. 2014a).

\subsection{Forelimb}

A high degree of convergence is present in the forelimb osteology of quadrupedal ornithischians. In all groups, the humeral head is restricted to the posterior surface of the humerus, so that the humerus was habitually retracted and could not have been protracted past the vertical (Maidment and Barrett 2012; Fig. 1). Stride length in quadrupedal ornithischians was probably strongly dictated by this constraint and, presumably, would have limited these animals to relatively slow locomotion. The deltopectoral crest of the humerus is enlarged and lengthened relative to its condition in bipedal groups, while the acromial process of the scapula moved posteriorly relative to the glenoid and was enlarged in ceratopsids and stegosaurs, and laterally everted in hadrosaurs and ankylosaurs (Maidment and Barrett 2012; Fig. 1). The M. deltoideus clavicularis (DCL) and the M. deltoideus scapularis (DSC) originated on the acromial process and scapula blade and inserted on the lateral surface of the deltopectoral crest, and these muscles retracted and abducted the humerus in basal ornithischians (Maidment and Barrett 2011). Movement of DSC cranially and DCL caudally in stegosaurs and ceratopsids resulted in a decrease in moment arms for retraction and abduction, and these muscles may have functioned primarily to 


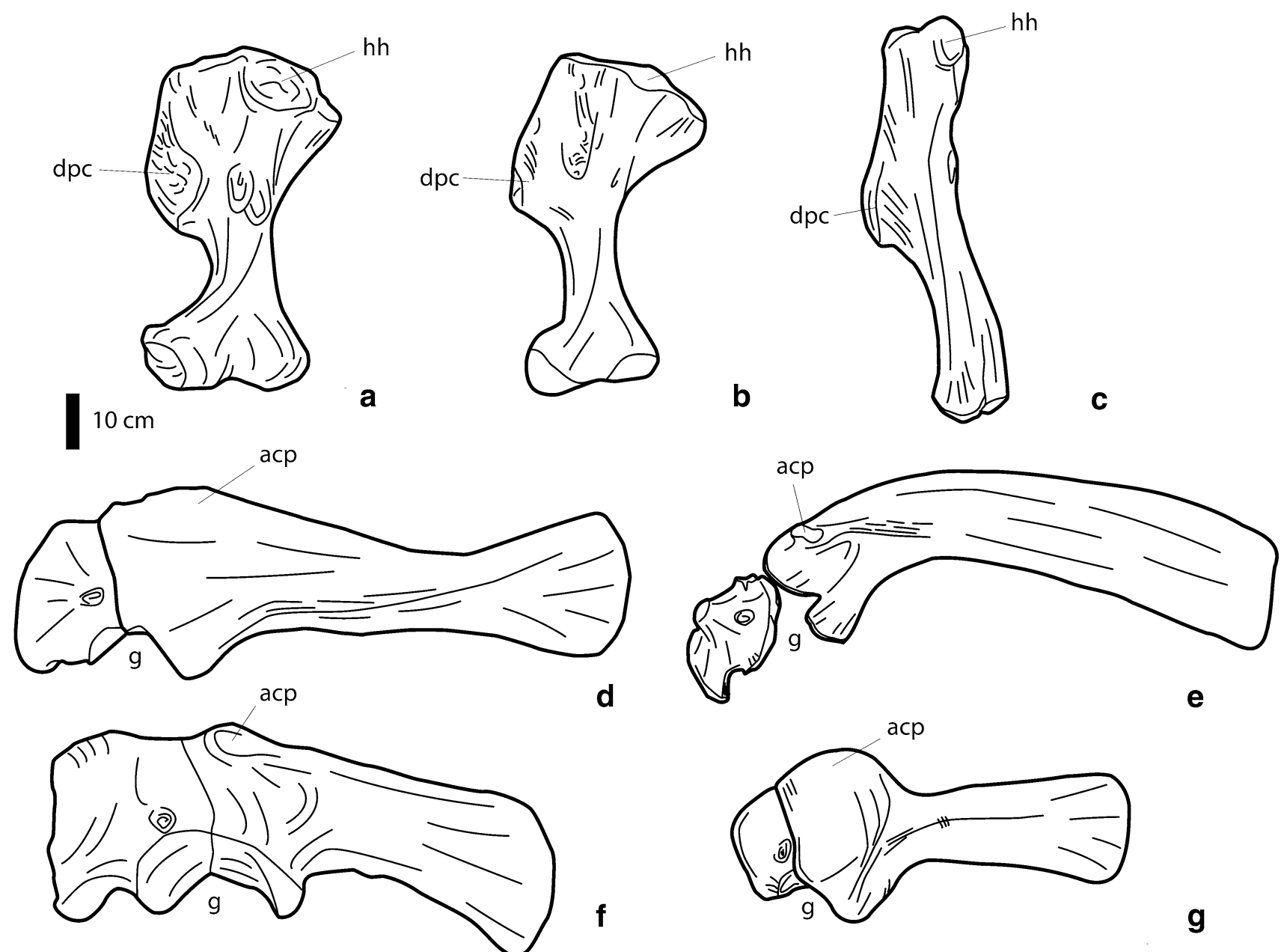

Fig. 1 Forelimb osteology in quadrupedal ornithischian dinosaurs. a Left humerus of the ankylosaurid ankylosaur Euoplocephalus in posterior view; b left humerus of the chasmosaurine ceratopsid Chasmosaurus in posterior view; c left humerus of the saurolophine hadrosaur Edmontosaurus in lateral view; d left scapulocoracoid of the chasmosaurine ceratopsid Chasmosaurus in lateral view; e left

laterally rotate the humerus in stegosaurs and ceratopsids. In contrast, in hadrosaurs and ankylosaurs, DCL and DSC retained moment arms for humeral abduction (Maidment and Barrett 2012).

Trackway data (Thompson and Holmes 2007) and evidence from manual pathologies (Rega et al. 2010) indicates that, during stance, the ceratopsid elbow was abducted from the parasagittal plane (but see Fujiwara and Hutchinson 2012 for an alternative view), and the similarity in both osteology and reconstructed myology between ceratopsids and stegosaurs makes this stance reasonable for stegosaurs also. Such a stance position would load weight on the medial side of the manus, and is supported by the observation that both stegosaurs and ceratopsids only possess hoof-like, weight-bearing ungual phalanges on the medial digits (Maidment and Barrett scapulocoracoid of the saurolophine hadrosaur Edmontosaurus in lateral view; f left scapulocoracoid of the ankylosaurid ankylosaur Euoplocephalus in lateral view; g left scapulocoracoid of the stegosaur Kentrosaurus in lateral view. acp acromial process, $d p c$ deltopectoral crest, $g$ glenoid, $h h$ humeral head. Scale bar equal to $10 \mathrm{~cm}$

2012). An analogous situation is observed in the hind limb during the evolution of sauropodomorph quadrupedalism: the first metatarsal of the basal sauropodomorph Aardonyx is hyper-robust, indicating weight-bearing was focused on the medial digits (Yates et al. 2010), and this is thought to be related to the evolution of a wide-gauged stance (Carrano 2005). Lateral rotation of the humerus by DCL and DSC in ceratopsids and stegosaurs would function to rotate the elbow towards the body, controlling abductive forces on the humerus by the ground reaction force (GRF) during stance and locomotion (Maidment and Barrett 2012).

In ankylosaurs, the limited available evidence suggests that all digits possessed weight-bearing, hoof-like manual ungual phalanges, and this observation and the differences in the osteology of the scapula and myology of DCL and DSC indicates a different stance for ankylosaurs from that 
of ceratopsids and stegosaurs (Maidment and Barrett 2012). Trackway data (McCrea et al. 2001) suggests that ankylosaurs placed their feet slightly lateral to the glenoid during locomotion. If the elbow of ankylosaurs was adducted during stance, and the long axis of the humerus held parallel to the parasagittal plane, the GRF would generate adductive forces at the glenoid during stance and locomotion, requiring the abductive control by DCL and DSC (Maidment and Barrett 2012). Hadrosaurs possessed narrower bodies than ankylosaurs, and they placed their feet on the midline during locomotion (Lockley and Wright 2001) meaning that the elbow would have been located medial to the glenoid during stance and locomotion. The GRF would have generated adductive forces around the glenoid, requiring abductive control by DCL and DSC (Maidment and Barrett 2012) in these taxa as well.

The manus of bipedal dinosaurs was supinated to allow for grasping (the primitive condition: Sereno 1997), but became pronated during the evolution of quadrupedality to allow weight-bearing. The development of an anterolateral process on the proximal ulna is indicative of this change in both ornithischians and sauropodomorphs (Yates et al. 2010; Maidment and Barrett 2014a). In taxa with an anterolateral process, the radius lies medial to the ulna, and the manus is pronated. Significant changes in lower-limb musculature presumably accompanied the change from supination to pronation, but lower-limb muscles are difficult to reconstruct due to lack of consistent osteological correlates in the extant phylogenetic bracket (Maidment

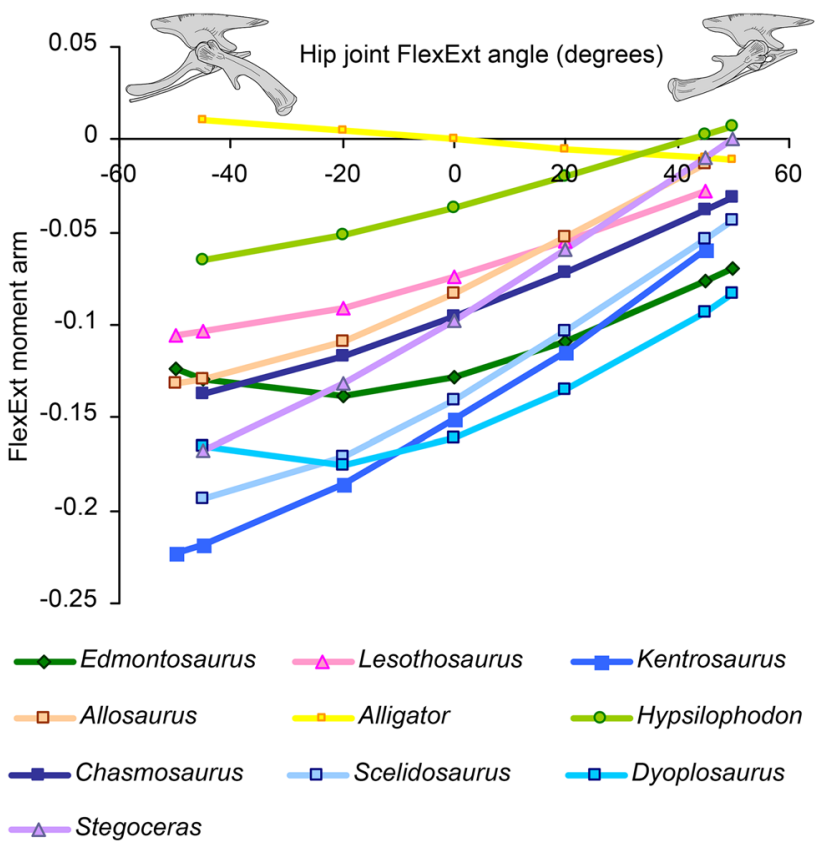

Fig. 3 The effect of changing iliac osteology on femoral protraction (hip flexion) muscle moment arms in the transition from quadrupedality to bipedality. Lesothosaurus, Hypsilophodon and Stegoceras are bipedal ornithischians, while Scelidosaurus, Dyoplosaurus, Kentrosaurus, Chasmosaurus and Edmontosaurus are quadrupeds. Alligator and Allosaurus represent extant archosaur and saurischian dinosaur outgroups, respectively. Flexion moment arms, normalized by femoral length, are plotted against a range of hip joint flexionextension angles for the M. puboischiofemoralis internus, part 1 . Note that the highest (most negative) flexion moment arms occur in quadrupedal ornithischians. Figure modified from Maidment et al. (2014a)
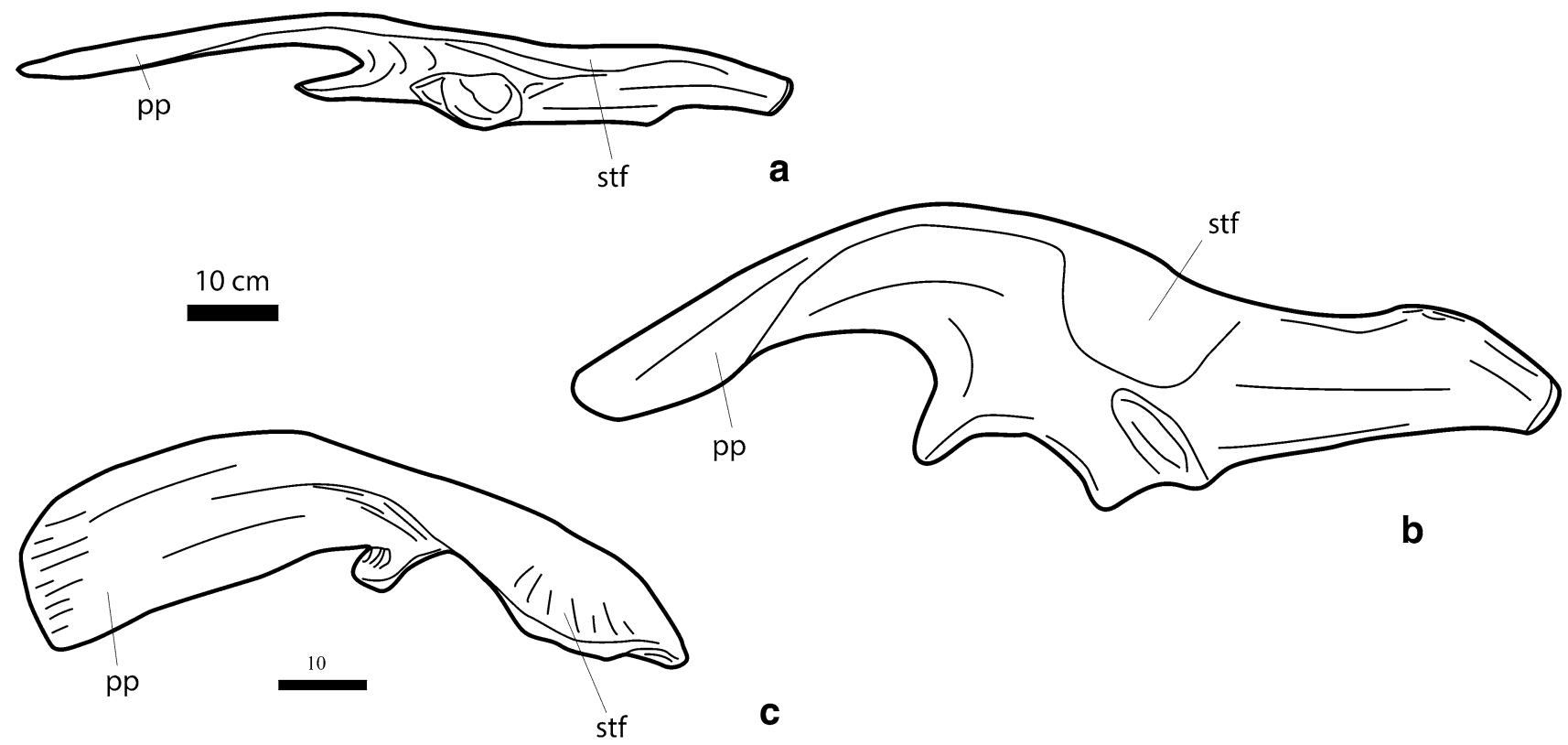

Fig. 2 Iliac osteology in quadrupedal ornithischian dinosaurs. Left ilia in lateral view; a the chasmosaurine ceratopsid Chasmosaurus; b the saurolophine hadrosaur Edmontosaurus; c the stegosaur
Kentrosaurus. pp preacetabular process, stf supratrochanteric flange. Scale bar equal to $10 \mathrm{~cm}$ 


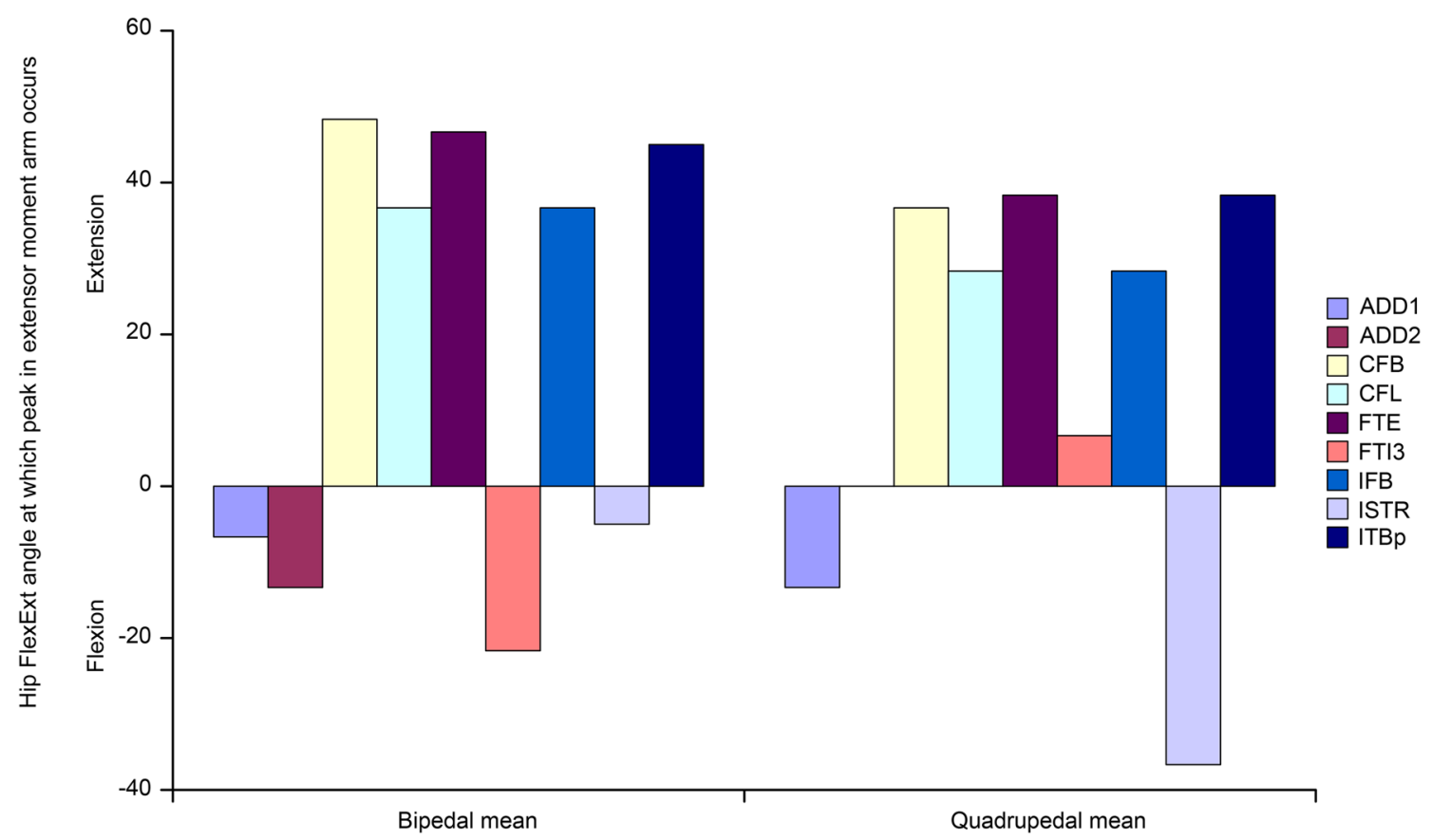

Fig. 4 Differences in the hip flexion-extension angle at which peak extensor (femoral retractor) muscle leverage occurs in quadrupedal and bipedal ornithischian dinosaurs. A negative hip angle indicates flexion (femoral protraction) while a positive angle indicates extension (femoral retraction). Peak extensor leverage occurs in the quadrupeds at hip angles closer to 0 degrees than in the bipeds. $A D D$

and Barrett 2011) and myological changes associated with this transition remain unstudied.

Changes to humerus morphology seem to occur before major morphological changes to the pectoral and pelvic girdles in all of the ornithischian groups in which quadrupedality occurred (Maidment and Barrett 2012). It may be that some steps in the order of morphological and accompanying myological change were constrained by the bipedal nature of the primitive ornithischian bauplan, but other characters appeared in different orders when compared across clades.

\subsection{Hind limb}

Elongation and ventral broadening of the preacetabular process of the ilium in thyreophorans and ceratopsids permitted an increase in surface area for attachment of the M. puboischiofemoralis internus (PIFI) and, presumably, an increase in the size of this muscle (Maidment and Barrett 2011, 2012; Fig. 2). PIFI functioned to protract and abduct the femur (Bates et al. 2012), and elongation of the preacetabular process in all groups of quadrupedal ornithischian increased the moment arm of this muscle for femoral protraction (Maidment et al. 2014a; Fig. 3). Maidment et al. (2014a) also found that the peak in femoral retractor moment arms occurred at more extended hip
M. adductor, $C F B$ M. caudofemoralis brevis, $C F L$ M. caudofemoralis longus, FTE M. femorotibialis externus, FTI3 M. femorotibialis internus, part 3, IFB M. iliofibularis, ISTR M. ischiotrochantericus, $I T B p$ M. iliotibialis, posterior part. Figure modified from Maidment et al. (2014a)

angles in quadrupedal ornithischians than in bipedal ornithischians (Fig. 4).

In quadrupedal thyreophorans and ceratopsids, the dorsal margin of the ilium is laterally everted to form the supratrochanteric flange (Maidment and Barrett 2012; Fig. 2). The dorsal margin of the ilium of hadrosaurs is also laterally everted, although not to the same degree as that of the other quadrupedal ornithischian groups (Maidment and Barrett 2012) and this also occurs in sauropods (Carrano 2005). This lateral eversion results in broadening of the trunk in quadrupedal thyreophorans and ceratopsids, and lateral movement of the origin of muscles that originate on the dorsal and lateral ilium, increasing moment arms for femoral abduction (Maidment et al. 2014a). Consequently, total abduction moment arms are higher for quadrupeds than they are for bipeds (Maidment et al. 2014a; Bates et al. 2015). Conversely, bipeds have higher total moment arms for adduction around the hip (Maidment et al. 2014a; Bates et al. 2015). Bates et al. (2015) found higher total lateral rotation moment arms in quadrupedal ornithischians than in bipedal ornithischians, and conversely higher medial rotation moment arms in bipedal ornithischians than in quadrupedal ornithischians. An osteological reason for this difference is not immediately obvious when muscle origins and insertions are compared, however. 
In summary, osteological changes that appear to be associated with the evolution of quadrupedality in ornithischians include elongation of the preacetabular process of the ilium and lateral eversion of its dorsal margin. Myological changes associated with the evolution of quadrupedality include an increase in the moment arm of PIFI for femoral protraction, a peak in femoral retractor moment arms at more extended hip angles than observed in bipedal taxa, increases in total abduction moment arms and concurrent decreases in adduction moment arms, and increases in total lateral rotation moment arms with decreases in total medial rotation moment arms.

Muscle function is dependent on a variety of physical assets such as muscle mass, architecture and contractile properties (Alexander 2003). The fossil record does not commonly preserve such data, and palaeontologists are limited to examining muscle force orientation to provide a foundation for understanding stance and locomotion in extinct animals. Such data will never allow a full picture of locomotor ability in extinct taxa to be elucidated. That being said, it is possible to speculate on how the changes identified above may have resulted in changes in function as quadrupedality evolved.

High abduction moment arms in quadrupedal ornithischians are related to lateral movement of the origins of muscles that primitively attached to the dorsal and lateral surfaces of the ilium. A consequence of lateral eversion of the dorsal margin of the ilium is broadening of the trunk in quadrupedal taxa. During locomotion, the force of the limbs on the substrate is opposed by an equal and opposite force, the GRF, the transverse component of which acts upwards from the foot, roughly through the long-axis of the limb (Hutchinson and Gatesy 2000). During locomotion, animals place their feet under or slightly medial to the hip, and the GRF thus produces a net adduction moment at the hip during stance. In an animal with a broad body, the adduction moment would be greater because the hip is further from the centre of mass (Maidment et al. 2014a). The large abduction moment arms modelled in quadrupedal taxa may therefore be needed to counter these larger adduction moments at the hip.

Alternatively, however, the modelled large abduction moments in quadrupedal ornithischians may be offset by a reduction in the size of some of the key abductor muscles, such as the M. iliofemoralis complex (IFM). Eversion of the supratrochanteric flange may have greatly reduced the available attachment surface area for these muscles (Maidment and Barrett 2012). While the size of the muscle attachment area is not unambiguously correlated with muscle size, it is possible that IFM was greatly reduced in quadrupedal thyreophorans, ceratopsids, and to a lesser extent, hadrosaurs (Maidment and Barrett 2012), and other muscles were required to take over as femoral abductors.
The peaks in femoral retractor moment arms at more highly extended hip angles in quadrupedal taxa than bipedal taxa are difficult to interpret due to a lack of data on correlations between retractor moment arm peaks and function in extant taxa (Maidment et al. 2014a). However, Hutchinson et al. (2005) have interpreted the peak in retractor moment arms as indicating the angle of the femur during stance phase, because high retraction moment arms would counter high protraction moments generated at the hip by the GRF. Based on this reasoning, a peak in femoral retraction moment arms at highly extended hip angles in quadrupedal taxa would indicate that the femur was held more vertically, and that the limb was more columnar, than in bipedal taxa.

A more columnar limb in stance phase in quadrupeds could also be used to explain why medial rotation moment arms might be lower in quadrupeds than in bipeds. In birds, medial rotation of the femur is used to counteract adductive forces generated about the hip by the GRF, because medial rotation of the almost horizontal femur results in lateral movements of the lower limb (Hutchinson and Gatesy 2000). If the femur is held vertically, however, medial rotation of the femur would only result in the toes turning medially (Maidment et al. 2014a). Quadrupedal ornithischians may, therefore, have de-emphasized medial rotation in favour of abduction as a means of controlling the adductive forces generated about the hip by the GRF.

A functional explanation for the increase in the moment arm of PIFI for femoral protraction is not immediately obvious. It is possible that PIFI took over as the main femoral protractor because the protraction moment arm of other muscles was de-emphasized due to lateral movement of their sites of origin, e.g. that of the anterior section of the M. iliotibialis (ITBa), although it is not clear that the moment arms of ITBa are significantly different in bipedal and quadrupedal taxa (Maidment et al. 2014a, supplementary online material).

\section{Limb scaling}

Bones are shaped by the forces that act upon them, so examining and comparing the shapes and relative proportions of limb bones should be informative about the forces that they experienced during life. Since all quadrupeds use their limbs predominantly for locomotion, it is not unreasonable to hypothesize that scaling relationships will be similar for all animals, and Carrano (1998, 2001) demonstrated that scaling patterns in mammals and dinosaurs were broadly similar. However, investigations into the limb bone scaling of quadrupedal ornithischians reveals contrasting scaling patterns that can be interpreted in light of differences in stance and locomotor style. 


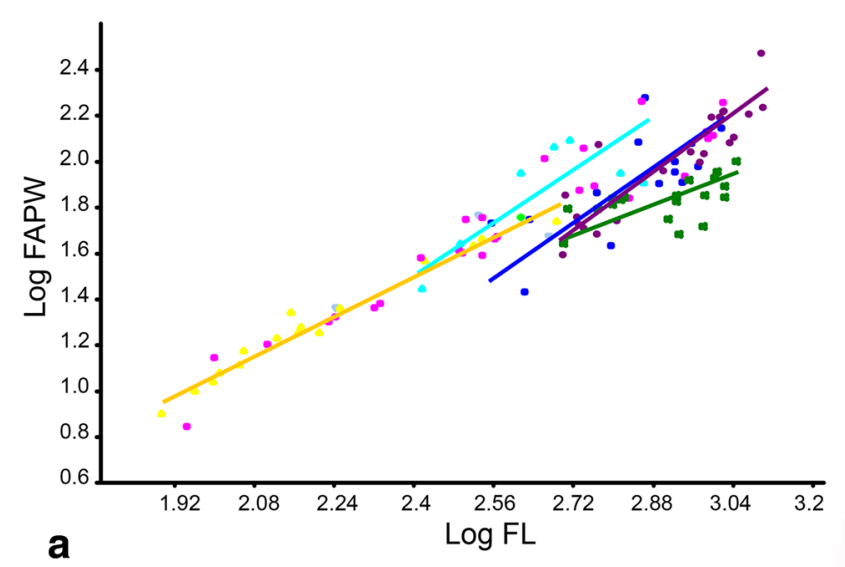

Hadrosauridae: $n=21 ; a=1.6 ; p=0.000$

Fig. 5 RMA regressions of femur length against width in major clades of quadrupedal ornithischians and in a paraphyletic assemblage of bipedal basal ornithischians. a Femur length regressed against the anteroposterior width of the femur at midshaft. Regression statistics are given below the graph; the allometric coefficient for groups not shown could not be distinguished from isometry at the $\mathrm{p}<0.05$ level. b Femur length regressed against the mediolateral width of the femur

The anteroposterior width of hadrosaur femora display positive allometry with respect to femoral length. In contrast, in ceratopsids the mediolateral width of the femur is positively allometric with respect to femoral length (Maidment et al. 2012; Fig. 5). Mediolateral eccentricity of the femoral midshaft is known in many large dinosaurs (Carrano 2001; 2005), and is attributed to a wide-gauged stance. In an animal with a wide body that places its foot lateral to the centre of mass during stance and locomotion, the transverse vector of the ground reaction force will be greater, and stress on the femur in a mediolateral orientation will be larger (Wilson and Carrano 1999; Carrano 2001, 2005). Positive allometry of the ceratopsid femur can thus be explained by a wide-gauged stance in these taxa. In contrast, hadrosaurs possessed a narrower body, and trackway evidence (Lockley and Wright 2001) indicates that they placed their feet on the midline during locomotion. In order for the forelimbs to reach the ground, hadrosaurs must have had a hind limb with a somewhat flexed hip. The GRF would have acted vertically from the foot to the centre of mass, and this would have generated stress in the femur in an anteroposterior direction (Maidment et al. 2012). The difference in scaling between hadrosaur and ceratopsid femora can therefore be explained by different stance and locomotor styles in these groups.

Likewise, in the humerus, both the mediolateral and anteroposterior width displays negative allometry with respect to length in stegosaurs, but positive allometry with respect to length in ceratopsids (Carrano 2005; Maidment

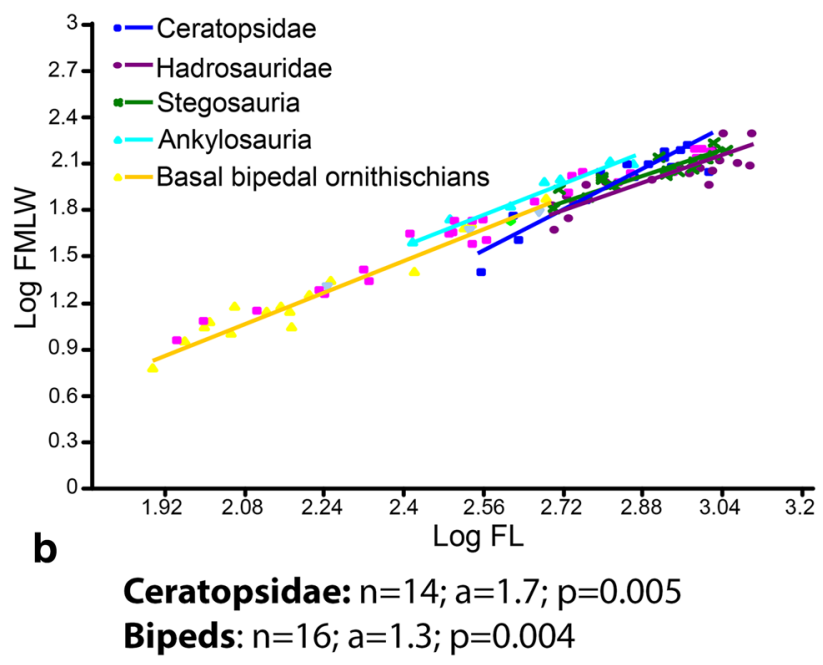

at midshaft. Regression statistics are given below the graph; the allometric coefficient for groups not shown could not be distinguished from isometry at the $\mathrm{p}<0.05$ level. $a$ allometric coefficient, FAPW femur anteroposterior width, $F L$ femoral length, $F M L W$ femur mediolateral width, $p$ probability that the allometric coefficient is equal to isometry, $n$ sample size. Figure modified from Maidment et al. (2012)

et al. 2012; Fig. 6). Differences in scaling could be related to differences in the position of the centre of mass between stegosaurs and ceratopsids: positive allometry in skull length with respect to body length has been recorded in ceratopsians (Sereno et al. 2007), and the centre of mass was located further anteriorly in ceratopsids than in stegosaurs, perhaps as a result of large head size (Maidment. et al. 2014b).

Furthermore, changes to limb bone proportions in hadrosaurs are not limited to phylogeny, but also occur within species during ontogeny. The hadrosaur Maiasaura displays positively allometric increases in humerus robustness and negatively allometric increases in femoral robustness through ontogeny, which have been interpreted to suggest that a greater proportion of body mass was borne by the forelimbs in larger individuals. This suggests a shift from bipedalism to quadrupedalism with maturity (Dilkes 2001, see above).

\section{Evolutionary drivers of ornithischian quadrupedality}

The acquisition of large body size has been viewed as a selective pressure favouring adoption of a quadrupedal stance (e.g. Sereno 1997), as greater body mass intuitively implies the need for greater structural support. Indeed, the largest terrestrial animals of all time, including not only dinosaurs but also gigantic mammals (such as proboscideans and indricotheres), were all quadrupedal (e.g. 


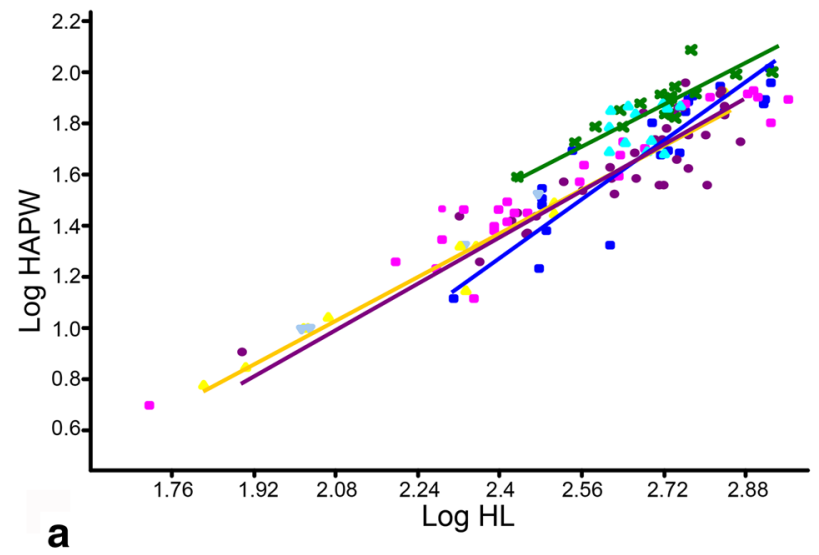

Stegosauria: $n=17 ; a=0.97 ; p=0.835$

Ceratopsidae: $n=23 ; a=1.44 ; p=0.005$

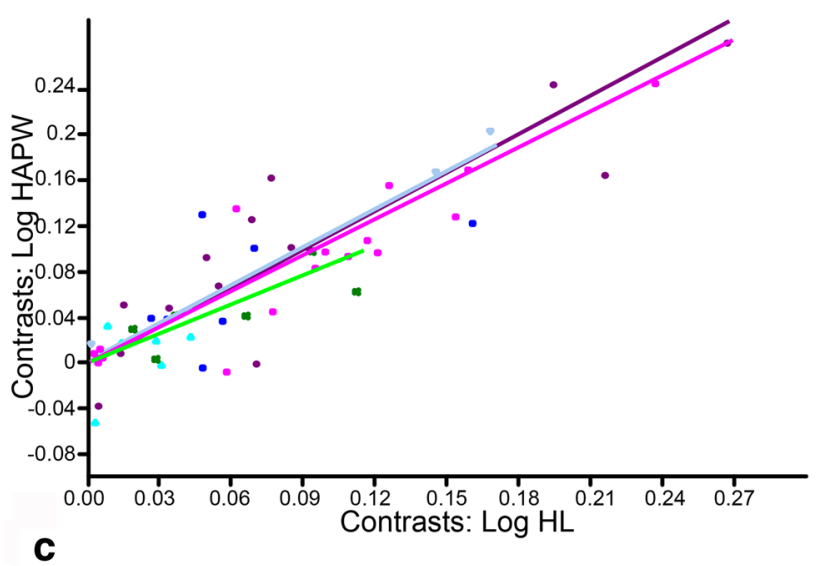

Stegosauria: $n=6 ; a=0.77 ; p=0.121$

Ceratopsidae: $n=7 ; a=1.06 ; p=0.798$

Fig. 6 RMA regressions of humerus length against width in major ornithischian clades and a paraphyletic assemblage of basal bipedal ornithischians. Regression statistics for Stegosauria and Ceratopsidae are given below the graphs. a Humerus length regressed against the minimum anteroposterior width of the humerus. Note that the allometric coefficient suggests isometry for Stegosauria but positive allometry in Ceratopsidae. b Humerus length regressed against the minimum mediolateral width of the humerus. Note that the allometric coefficient suggests isometry for Stegosauria but positive allometry in

Fortelius and Kappelman 1993; Sander et al. 2011). However, a brief survey of dinosaur evolutionary history demonstrates that increased body size per se cannot have been the primary driver for ornithischian quadrupedality in the majority of cases. In most ornithischian clades, including Ceratopsia, Rhabdodontidae and Thyreophora, these transitions occurred at relatively small body sizes: quadrupedal basal ceratopsians, such as Leptoceratops and Protoceratops, range from around $80-400 \mathrm{~kg}$ in weight (Benson et al. 2014), rhabdodontid ornithopods weigh 31-120 kg (Benson et al. 2014) and Scelidosaurus weighed

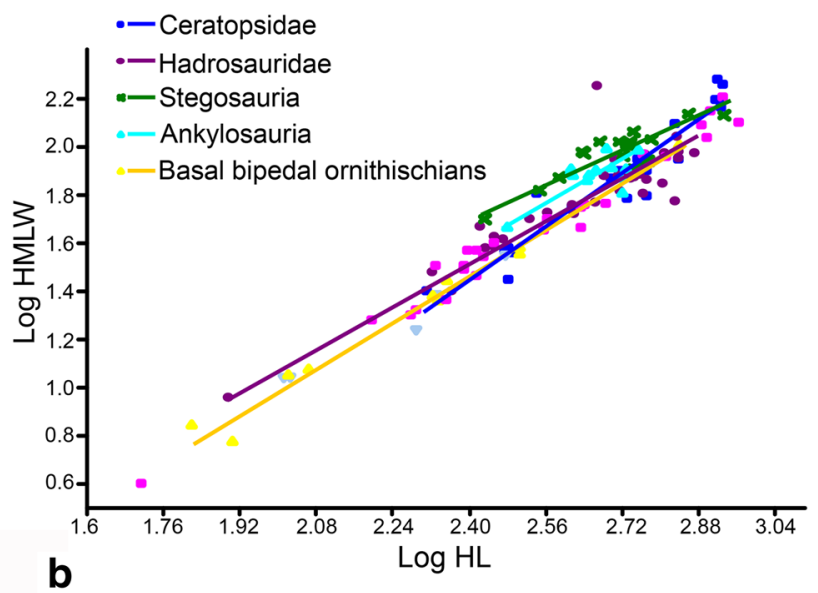

Stegosauria: $\mathrm{n}=17 ; \mathrm{a}=0.92 ; \mathrm{p}=0.5$

Ceratopsidae: $\mathrm{n}=23 ; \mathrm{a}=1.41 ; \mathrm{p}=0.000$

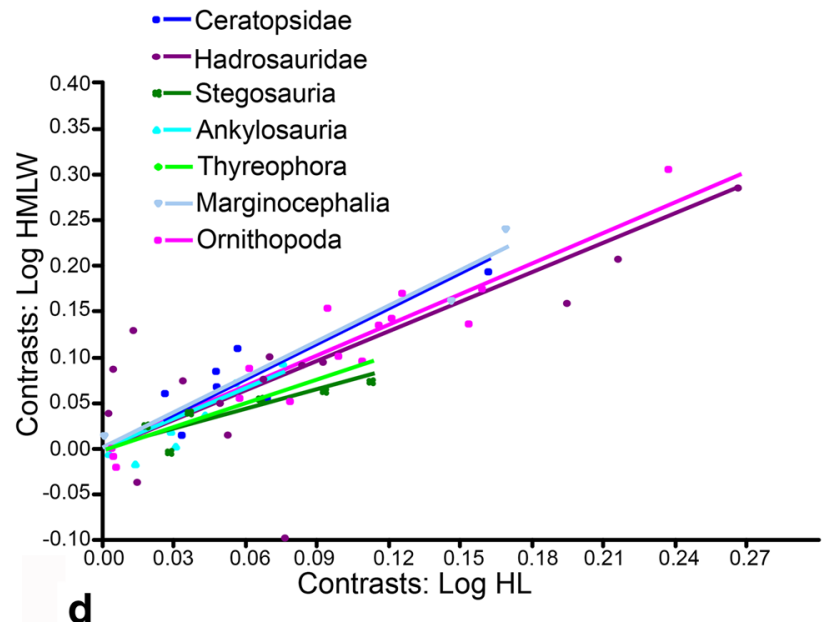

Stegosauria: $n=6 ; a=0.69 ; p=0.012$

Ceratopidae: $n=7 ; a=1.28 ; p=0.084$

Ceratopsidae. c, d The same regression analyses as in a and b respectively, but taking into account phylogeny using phylogenetically independent contrasts. Negative allometry of the humerus is more strongly expressed in Stegosauria, and statistically significant in d, while isometry or positive allometry is indicated for Ceratopsidae. $a$ allometric coefficient, $H A P W$ humerus anteroposterior width, $H L$ humerus length, $H M L W$ humerus mediolateral width, $p$ probability that the allometric coefficient is equal to isometry, $n$ sample size. Figure modified from Maidment et al. (2012)

up to $320 \mathrm{~kg}$ (Maidment. et al. 2014b). These body masses are much lower than those of many bipedal dinosaurs, including those that reached body masses $>1000 \mathrm{~kg}$, as in many allosauroids, megalosauroids, tyrannosauroids and a variety of basal sauropodomorphs (Benson et al. 2014). The only transition to quadrupedality associated with large body size occurs within Iguanodontia, which, paradoxically, includes taxa that lack many of the graviportal/ weight-bearing features seen in other quadrupedal dinosaurs (e.g. Galton 1970; Coombs 1978). If size alone were an important driver of quadrupedality we might expect this 
feature to have arisen multiple times in Theropoda, but it has never appeared within this clade (recent controversial claims for quadrupedality in Spinosaurus notwithstanding: Ibrahim et al. 2014). Large body size is correlated with quadrupedality in sauropods (e.g. Carrano 2005; Sander et al. 2011), but this group achieved quadrupedal stance at similar body masses to those attained by some bipedal basal sauropodomorphs (for example, Riojasaurus and Antetonitrus both have femoral lengths of approximately $780-790 \mathrm{~mm}$, but the former is bipedal and the latter quadrupedal: see Bonaparte 1972; Yates and Kitching 2003). Moreover, at least one dinosaur taxon, the basal sauropodomorph Massospondylus, exhibits the contrary trend of abandoning quadrupedality as body mass increased (Reisz et al. 2005). These observations imply that simplistic mechanistic explanations based on body mass alone are inadequate to explain ornithischian quadrupedality. Nevertheless, although large body size did not drive the initial evolution of quadrupedality, it is still possible that quadrupedality might have facilitated the later evolution of large body size in the clade [see Sander et al. (2011) and Sander (2013) for discussion on the links between quadrupedality and body size evolution in sauropods].

Two other hypotheses have been proposed to account for the loss of bipedalism: the acquisition of extensive dermal armour in thyreophorans (Colbert 1981) and the development of relatively large head size in ceratopsians (Sereno et al. 2007). In both cases, these hypotheses can be tested by determining and comparing the position of the centre of mass $(\mathrm{CoM})$ in bipedal and quadrupedal members of each clade. In bipeds, it would be expected that the CoM is positioned above the feet to enable to animal to stand in equilibrium. This constraint should not apply to quadrupeds and the CoM would be free to move anteriorly in these taxa so that body mass is more equally distributed between the fore- and hind limbs (Maidment. et al. 2014b). Maidment et al. (2014b) developed a series of virtual 3D models for a variety of bipedal and quadrupedal taxa and determined their CoMs using 3D mathematical slicing (Henderson 1999). In addition, several theoretical models of 'hopeful monsters' were also constructed, including bipedal taxa with increased head size or additional loads of postcranial osteoderms (Maidment. et al. 2014b). These experiments showed that: (1) the CoM in uncontroversial ornithischian bipeds is situated above the feet; (2) the CoM in some undoubted quadrupeds, such as ceratopsids, is shifted anteriorly; and (3) that adding osteoderms to a 'standard' bipedal ornithischian did not cause anterior movement of the CoM. The latter observation indicates that the development of (even extensive) dermal armour is unlikely to have been the primary cause of thyreophoran quadrupedality (Maidment. et al. 2014b). However, increasing the head size of a theoretical bipedal ceratopsian model did result in an anterior migration of the CoM beyond the level of the feet, implying that the evolution of large head size might result in a structural need to adopt a quadrupedal pose (Maidment. et al. 2014b; Fig. 7), supporting the proposal of Sereno et al. (2007). It is interesting to note that the development of large head size and associated cranial ornamentation (frills, horns) in ceratopsians is usually associated with sexual selection or behavioural evolution, so this could be an example of social or sexual
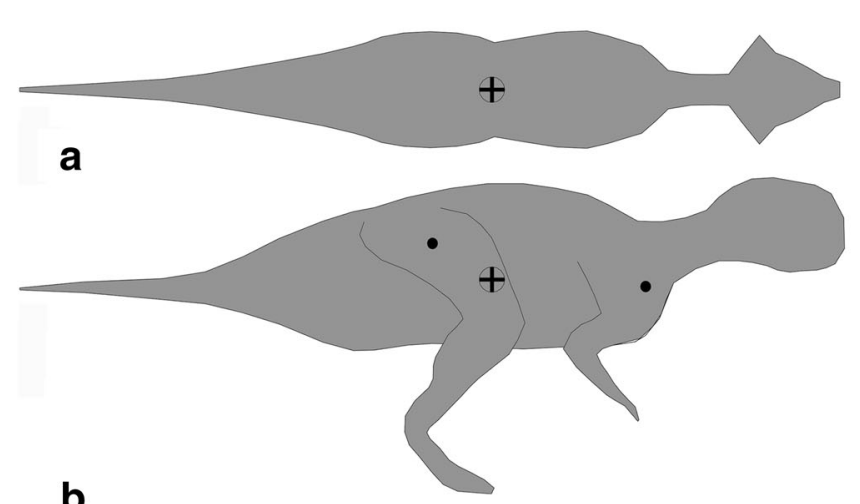

\section{$\rightarrow$ Body CoM}

\section{- Location of glenoid/acetabulum}

Fig. 7 Dorsal (a, c) and lateral $(\mathbf{b}, \mathbf{d})$ views of mathematical models of Psittacosaurus. a, b Psittacosaurus; c, d Psittacosaurus reconstructed with the frill and horns of Chasmosaurus. The black cross indicates centre of mass $(\mathrm{CoM})$. CoM is located $6 \mathrm{~mm}(3 \%$ of

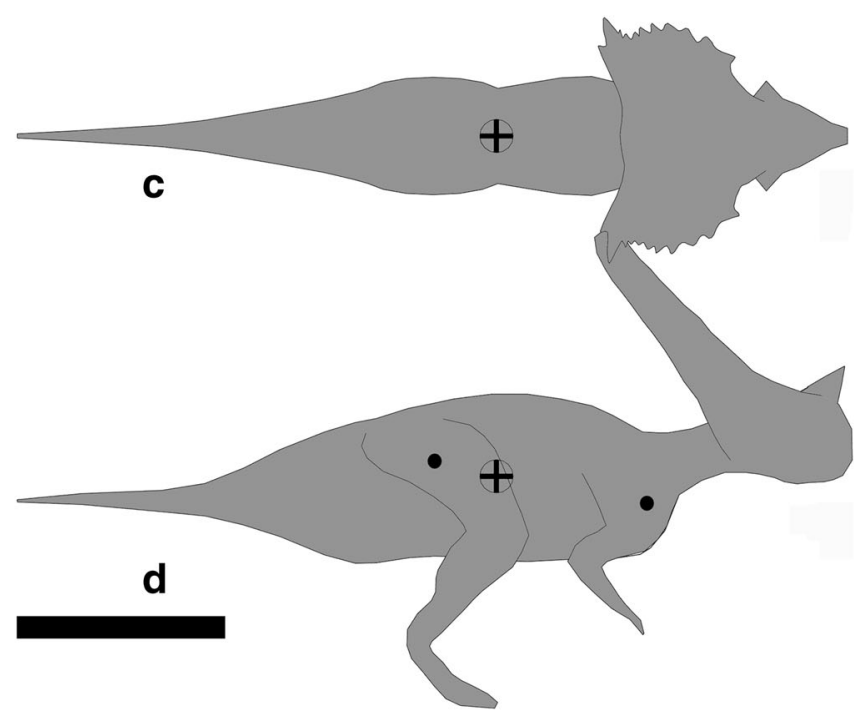

glenoacetabular distance) further anteriorly in $\mathbf{c}$ and $\mathbf{d}$, and lies just anterior to the toes, indicating that this 'hybrid' animal would not have been able to walk bipedally. Scale bar is equal to $25 \mathrm{~cm}$. Figure modified from Maidment et al. (2014b) 
selection driving a major change in overall body plan (Sereno et al. 2007). Interestingly, the CoM also migrates anteriorly in sauropodomorph evolution, due to the evolution of heavier, more elongate necks and more robust forelimbs and pectoral regions (Bates et al. 2016). This anterior movement correlates with the shift from bipedality in basal sauropodomorphs to the adoption of quadrupedalism in sauropods (Bates et al. 2016) and this might be a better explanation for the origin of sauropod quadrupedality than straightforward increases in body size.

Finally, it is potentially noteworthy that all dinosaur quadrupeds were herbivores (Barrett 2014). It is likely that the adoption of obligate, high-fibre herbivorous diets required the evolution of elongate and complex digestive tracts to enable longer passage times/and or more efficient processing of food in the gut, as occurs in living herbivorous squamates, birds and mammals (Stevens and Hume 1995). Gut elongation or increase in relative gut size could have been a factor driving the anterior position of the CoM and is hinted at by the relatively longer and wider trunk regions of quadrupeds relative to those of bipeds (e.g. Galton 1970; Weishampel and Norman 1989; Norman and Weishampel 1991; Maidment. et al. 2014b). Although many bipedal ornithischians were also herbivorous (or omnivorous: Barrett 2000) these taxa were also more likely to be selective feeders on lower-fibre or higher energy foodstuffs, as indicated by narrower snouts similar to those of extant selective browsers and grazers (e.g. Norman and Weishampel 1991). Consequently, the feeding strategies of small bipedal ornithischians might have enabled them to retain the primitive dinosaurian condition, while the more derived condition of high-fibre herbivory led to quadrupedality. A shift to obligate high-fibre herbivory has also been linked to the development of sauropod quadrupedality for similar reasons, with the need to turn the body into an efficient fermentation chamber (e.g. Hummel et al. 2008; Wilkinson and Ruxton 2013). All known herbivorous non-avian theropods retain bipedality but, as with bipedal ornithischians, many of these taxa are narrow-snouted and might have been selective or specialist feeders, although it should be noted that therizinosaurs do possess deep thoraxes and laterally flared ilia suggestive of elongate guts (Paul 1984; Barrett 2005; Zanno and Makovicky 2011; Lautenschlager et al. 2016). Nevertheless, in the absence of good information on dinosaur gastrointestinal tracts this suggestion must remain tentative for now. These potential interactions between posture, diet and gastrointestinal morphology can be envisaged as forming a series of interconnected positive feedback loops and it is plausible that locomotion and diet might have evolved in a correlated manner via an 'evolutionary cascade' or 'correlated progression' model (Kemp 2007; Barrett and Upchurch 2007; Sander 2013; Barrett 2014).

\section{Conclusions}

Although superficially similar in many aspects of their limb and girdle anatomy, quadrupedal ornithischians acquired these features convergently and assembled these functional complexes in each clade in different ways at different times (Maidment and Barrett 2012, 2014a). Moreover, despite the many similarities between them in terms of osteology and gross myology, there were some substantial differences in locomotor function, such as differences in habitual foreand hind limb stance during the support phase and in the functions of individual muscles. These differences were elucidated following detailed consideration of muscle function and biomechanical modelling, but are not necessarily obvious on the basis of gross morphology alone (Maidment and Barrett 2012; Maidment et al. 2014a). These observations underscore the need for caution when inferring the biomechanics of extinct taxa, as interpreting hard tissue morphology in the absence of detailed knowledge on muscle function and neurology can lead to misleading conclusions: organismal form cannot always be used as a reliable proxy for detailed functional inference (e.g. Lauder 1995; Maidment and Barrett 2012; Lautenschlager et al. 2016).

Although the various morphological and functional changes associated with secondary quadrupedality are now beginning to be characterised, the evolutionary drivers for this unusual phenomenon remain elusive. Some mechanisms, like simple increases in body size, can be ruled out, but others, such as increases in head, neck or gut size, seem plausible (Sereno et al. 2007; Maidment et al. 2014a, b; Bates et al. 2016). Comparisons between ornithischian and sauropodomorph quadrupeds reveal striking convergences between these clades (e.g. in the anterior migration of the $\mathrm{CoM}$, osteological changes to the fore- and hind limbs and ilia, and concurrent changes in muscle architecture). More detailed biomechanical work is also required on the locomotor transition within Sauropodomorpha in order to gain a better understanding of dinosaur locomotor evolution as a whole and to shed more light on the evolutionary drivers of secondary quadrupedality.

Acknowledgements We thank Fidel Torcida Fernández-Baldor and the other organisers of the VII Journadas Internacionales sobre Paleontologia de Dinosaurios y su Entorno for inviting PMB to attend the meeting and for the opportunity to contribute to this volume. PMB was funded by a grant from the NHM Earth Science Departmental Investment Fund. The work underpinning this paper has benefitted from many discussions and collaborations, primarily with Karl Bates and Donald Henderson, but also including Vivian Allen, Victoria Arbour, Debi Linton, Peter Falkingham, John Hutchinson, Emma Schachner, Paul Upchurch and Collin VanBuren. We thank Donald Henderson and Martin Lockley for their comments on an earlier version of this contribution. Francisco Gascó kindly translated the 
abstract into Spanish. This was work was supported by NERC Grant NE/G001898/1.

Open Access This article is distributed under the terms of the Creative Commons Attribution 4.0 International License (http://crea tivecommons.org/licenses/by/4.0/), which permits use, duplication, adaptation, distribution and reproduction in any medium or format, as long as you give appropriate credit to the original author(s) and the source, provide a link to the Creative Commons license and indicate if changes were made.

\section{References}

Alexander, R. McN. (1976). Estimates of speeds of dinosaurs. Nature, 261, 129-130.

Alexander, R. McN. (1985). Mechanics of posture and gait of some large dinosaurs. Zoological Journal of the Linnean Society, 83, $1-25$.

Alexander, R. McN. (2003). Principles of animal locomotion. Princeton: Princeton University Press.

Barrett, P. M. (2000). Prosauropods and iguanas: speculation on the diets of extinct reptiles. In H.-D. Sues (Ed.), The evolution of herbivory in terrestrial vertebrates (pp. 42-78). Cambridge: Cambridge University Press.

Barrett, P. M. (2005). The diet of ostrich dinosaurs (Theropoda: Ornithomimosauria). Palaeontology, 48, 347-358.

Barrett, P. M. (2014). Paleobiology of herbivorous dinosaurs. Annual Reviews of Earth and Planetary Science, 42, 207-230.

Barrett, P. M., \& Upchurch, P. (2007). The evolution of feeding mechanisms in early sauropodomorph dinosaurs. Special Papers in Palaeontology, 77, 91-112.

Bates, K. T., Maidment, S. C. R., Allen, V., \& Barrett, P. M. (2012). Computational modelling of locomotor muscle moment arms in the basal dinosaur Lesothosaurus diagnosticus: Assessing convergence between birds and basal ornithischians. Journal of Anatomy, 220, 212-232.

Bates, K., Maidment, S. C. R., Schachner, E. R., \& Barrett, P. M. (2015). Comments and corrections on 3D modeling studies of locomotor muscle moment arms in archosaurs. PeerJ, 3, e1272. https://doi.org/10.7717/peerj.1272.

Bates, K. T., Mannion, P. D., Falkingham, P. L., Brusatte, S. L., Hutchinson, J. R., Otero, A., et al. (2016). Temporal and phylogenetic evolution of the sauropod body plan. Royal Society Open Science, 3, 150636. https://doi.org/10.1098/rsos.150636.

Benson, R. B. J., Campione, N. E., Carrano, M. T., Mannion, P. D., Sullivan, C., Upchurch, P., et al. (2014). Rates of dinosaur body mass evolution indicate 170 million years of sustained ecological innovation on the avian stem lineage. PLoS Biology, 12, e1001853. https://doi.org/10.1371/journal.pbio.1001853.

Bonaparte, J. F. (1972). Los tetrapodos del sector superior de la formacion Los Colorados, La Rioja, Argentina, (Triásico Superior). Opera Lilloana, 22, 1-183.

Bonnan, M. F. (2003). The evolution of manus shape in sauropod dinosaurs: Implications for functional morphology, forelimb orientation, and phylogeny. Journal of Vertebrate Paleontology, 23, 595-613.

Bonnan, M. F., \& Yates, A. M. (2007). A new description of the forelimb of the basal sauropodomorph Melanorosaurus: Implications for the evolution of pronation, manus shape and quadrupedalism in sauropod dinosaurs. Special Papers in Palaeontology, 77, 157-168.

Carpenter, K., \& Wilson, Y. (2008). A new species of Camptosaurus (Dinosauria: Ornithischia) from the Morrison Formation (Upper Jurassic) of Dinosaur National Monument, Utah, and a biomechanical analysis of its forelimb. Annals of the Carnegie Museum, 76, 227-263.

Carrano, M. T. (1998). Locomotion in non-avian dinosaurs: Integrating data from hindlimb kinematics, in vivo strains, and bone morphology. Paleobiology, 24, 450-469.

Carrano, M. T. (2001). Implications of limb bone scaling, curvature and eccentricity in mammals and non-avian dinosaurs. Journal of Zoology, 254, 41-55.

Carrano, M. T. (2005). The evolution of sauropod locomotion: morphological diversity of a secondarily quadrupedal radiation. In K. A. Curry Rogers \& J. A. Wilson (Eds.), The sauropods: Evolution and paleobiology (pp. 229-249). Berkeley: University of California Press.

Castanera, D., Vila, B., Razzolini, N. L., Falkingham, P. L., Canudo, J. I., Manning, P. L., et al. (2013). Manus track preservation bias as a key factor for assessing trackmaker identity and quadrupedalism in basal sauropods. PLoS One, 8, e54177. https://doi.org/10.1371/journal.pone.0054177.

Chinnery, B. J. (2004). Morphometric analysis of evolutionary trends in the ceratopsian postcranial skeleton. Journal of Vertebrate Paleontology, 24, 591-609.

Colbert, E. H. (1964). Relationships of the saurischian dinosaurs. American Museum Novitates, 2181, 1-24.

Colbert, E. H. (1981). A primitive ornithischian dinosaur from the Kayenta Formation of Arizona. Bulletin of the Museum of Northern Arizona, 53, 1-61.

Coombs, W. P., Jr. (1978). Theoretical aspects of cursorial adaptations in dinosaurs. Quarterly Review of Biology, 51, 393-418.

Dilkes, D. W. (2001). An ontogenetic perspective on locomotion in the Late Cretaceous dinosaur Maiasaura peeblesorum (Ornithischia: Hadrosauridae). Canadian Journal of Earth Sciences, 38, $1205-1227$.

Falkingham, P. L., Bates, K. T., Margetts, L., \& Manning, P. L. (2011). The 'Goldilocks' effect: preservation bias in vertebrate track assemblages. Journal of the Royal Society, Interface, 8, $1142-1154$.

Fortelius, M., \& Kappelman, J. (1993). The largest land animal ever imagined. Zoological Journal of the Linnean Society, 108, 85-101.

Fujiwara, S., \& Hutchinson, J. R. (2012). Elbow joint adductor moment arm as an indicator of forelimb posture in extinct quadrupedal tetrapods. Proceedings of the Royal Society B, 279, 2561-2570.

Galton, P. M. (1970). The posture of hadrosaurian dinosaurs. Journal of Paleontology, 44, 464-473.

Gatesy, S. M. (1990). Caudofemoral musculature and the evolution of theropod locomotion. Paleobiology, 16, 170-186.

Gatesy, S. M., Middleton, K. M., Jenkins, F. A., Jr., \& Shubin, N. H. (1999). Three-dimensional preservation of foot movements in Triassic theropod dinosaurs. Nature, 399, 141-144.

Henderson, D. M. (1999). Estimating the masses and centres of mass of extinct animals by 3-D mathematical slicing. Paleobiology, $25,88-106$.

Hone, D. W. E. (2012). Variation in the tail length of non-avian dinosaurs. Journal of Vertebrate Paleontology, 32, 1082-1089.

Hummel, J., Gee, C. T., Südekum, K.-H., Sander, P. M., Nogge, G., \& Clauss, M. (2008). In vitro digestibility of fern and gymnosperm foliage: Implications for sauropod feeding ecology and diet selection. Proceedings of the Royal Society B, 275, 1015-1021.

Hutchinson, J. R., Anderson, F. C., Blemker, S. S., \& Delp, S. L. (2005). Analysis of hindlimb muscle moment arms in Tyrannosaurus rex using a three-dimensional musculoskeletal computer model: Implications for stance, gait and speed. Paleobiology, 31, 676-701.

Hutchinson, J. R., \& Garcia, M. (2002). Tyrannosaurus was not a fast runner. Nature, 415, 1018-1021. 
Hutchinson, J. H., \& Gatesy, S. M. (2000). Adductors, abductors and the evolution of archosaur locomotion. Paleobiology, 26, 734-751.

Ibrahim, N., Sereno, P. C., Dal Sasso, C., Maganuco, S., Fabbri, M., Martill, D. M., et al. (2014). Semiaquatic adaptations in a giant predatory dinosaur. Science, 345, 1613-1616.

Kemp, T. S. (2007). The concept of correlated progression as the basis of a model for the evolutionary origin of major new taxa. Proceedings of the Royal Society B, 274, 1667-1673.

Langer, M. C., Nesbitt, S. J., Bittencourt, J. S., \& Irmis, R. B. (2013). Non-dinosaurian Dinosauromorpha. In S. J. Nesbitt, J. B. Desojo, \& R. B. Irmis (Eds.), Anatomy, phylogeny, and palaeobiology of early archosaurs and their kin (pp. 157-186). London: Geological Society of London.

Lauder, G. V. (1995). On the inference of function from structure. In J. J. Thomason (Ed.), Functional morphology in vertebrate paleontology (pp. 1-9). Cambridge: Cambridge University Press.

Lautenschlager, S., Brassey, C. A., Button, D. J., \& Barrett, P. M. (2016). Decoupled form and function in disparate herbivorous dinosaur clades. Scientific Reports, 6, e26495. https://doi.org/10. 1038/srep26495.

Lockley, M. G. (1991). Tracking dinosaurs: A new look at an ancient world. Cambridge: Cambridge University Press.

Lockley, M. G. (2007). The morphodynamics of dinosaurs, other archosaurs, and their trackways: Holistic insights into relationships between feet, limbs, and the whole body. SEPM Special Publication, 88, 27-51.

Lockley, M. G., \& Hunt, A. P. (1995). Ceratopsid tracks and associated ichnofauna from the Laramie Formation (Upper Cretaceous: Maastrichtian) of Colorado. Journal of Vertebrate Paleontology, 15, 592-614.

Lockley, M. G., \& Wright, J. L. (2001). Trackways of large quadrupedal ornithopods from the Cretaceous: A review. In D. H. Tanke \& K. Carpenter (Eds.), Mesozoic vertebrate life (pp. 428-442). Bloomington: Indiana University Press.

Maidment, S. C. R., \& Barrett, P. M. (2011). The locomotor musculature of basal ornithischian dinosaurs. Journal of Vertebrate Paleontology, 31, 1265-1291.

Maidment, S. C. R., \& Barrett, P. M. (2012). Does morphological convergence imply functional similarity? A test using the evolution of quadrupedalism in ornithischian dinosaurs. Proceedings of the Royal Society B, 279, 3765-3771.

Maidment, S. C. R., \& Barrett, P. M. (2014). Osteological correlates for quadrupedality in ornithischian dinosaurs. Acta Palaeontologica Polonica, 59, 53-70.

Maidment, S. C. R., Bates, K. T., Falkingham, P. L., VanBuren, C., Arbour, V., \& Barrett, P. M. (2014a). Locomotion in ornithischian dinosaurs: An assessment using three-dimensional computational modelling. Biological Reviews, 89, 588-617.

Maidment, S. C. R., Henderson, D. M., \& Barrett, P. M. (2014b). What drove reversions to quadrupedality in ornithischian dinosaurs? Testing hypotheses using centre of mass modelling. Naturwissenschaften, 101, 989-1001.

Maidment, S. C. R., Linton, D., Upchurch, P., \& Barrett, P. M. (2012). Limb-bone scaling indicates diverse stance and gait in quadrupedal ornithischian dinosaurs. PLoS One, 7, e36904. https://doi.org/10.1371/journal.pone.0036904.

McCrea, R. T., Lockley, M. G., \& Meyer, C. A. (2001). Global distribution of purported ankylosaur track occurrences. In K. Carpenter (Ed.), The armored dinosaurs (pp. 413-454). Bloomington: Indiana University Press.

Norman, D. B. (1980). On the ornithischian dinosaur Iguanodon bernissartensis from the Lower Cretaceous of Bernissart (Belgium). Mémoire de l'Institute Royal des Sciences Naturelles de Belgique, 178, 1-103.
Norman, D. B. (1986). On the anatomy of Iguanodon atherfieldensis (Ornithischia: Ornithopoda). Bulletin de l'Institute Royal des Sciences Naturelles de Belgique: Sciences de la Terre, 56, 281-372.

Norman, D. B., \& Weishampel, D. B. (1991). Feeding mechanisms in some small herbivorous dinosaurs: Processes and patterns. In J. M. V. Rayner \& R. J. Wootton (Eds.), Biomechanics in Evolution (pp. 161-181). Cambridge: Cambridge University Press.

Owen, R. (1861). Monograph on the British fossil Reptilia from the Oolitic Formations. Part One. A monograph of a fossil dinosaur (Scelidosaurus harrisonii, Owen). Palaeontographical Society Monographs, 13 (Number 56), 1-14 + pls 1-16.

Paul, G. S. (1984). The segnosaurian dinosaurs: Relics of the prosauropod-ornithischian transition? Journal of Vertebrate Paleontology, 4, 507-515.

Rega, E., Holmes, R. B., \& Tirabaso, A. (2010). Habitual locomotor behaviour inferred from manual pathology in two Late Cretaceous chasmosaurine ceratopsid dinosaurs, Chasmosaurus irvinensis (CMN41357) and Chasmosaurus belli (ROM 843). In M. J. Ryan, B. J. Chinnery Allgeier, \& D. A. Eberth (Eds.), New perspectives on horned dinosaurs (pp. 340-354). Bloomington: Indiana University Press.

Reisz, R. R., Scott, D., Sues, H.-D., Evans, D. C., \& Raath, M. A. (2005). Embryos of an early jurassic prosauropod dinosaur and their evolutionary significance. Science, 309, 761-764.

Sander, P. M. (2013). An evolutionary cascade model for sauropod gigantism-overview, update and tests. PLoS One, 8, e78573. https://doi.org/10.1371/journal.pone.0078573.

Sander, P. M., Christian, A., Clauss, M., Fechner, R., Gee, C. T., Griebeler, E.-M., et al. (2011). Biology of the sauropod dinosaurs: The evolution of gigantism. Biological Reviews, 86, $117-155$.

Sellars, W. I., \& Manning, P. L. (2007). Estimating dinosaur running speeds using evolutionary robotics. Proceedings of the Royal Society B, 274, 2711-2716.

Sellars, W. I., Manning, P. L., Lyson, T., Stevens, K., \& Margetts, L. (2009). Virtual palaeontology: gait reconstruction of extinct vertebrates using high performance computing. Palaeontologia Electronica, 12(3), 11A http://palaeo-electronica.org/2009_3/ 180/index.html.

Senter, P. (2007). Analysis of forelimb function in basal ceratopsians. Journal of Zoology, 273, 305-314.

Sereno, P. C. (1997). The origin and evolution of dinosaurs. Annual Reviews of Earth and Planetary Science, 25, 435-489.

Sereno, P. C. (1999). The evolution of dinosaurs. Science, 284, 2137-2147.

Sereno, P. C., Zhao, X.-J., Brown, L., \& Tan, L. (2007). New psittacosaurid highlights skull enlargement in horned dinosaurs. Acta Palaeontologica Polonica, 52, 275-284.

Stevens, C. E., \& Hume, I. D. (1995). Comparative physiology of the vertebrate digestive system (2nd ed.). Cambridge: Cambridge University Press.

Thompson, S., \& Holmes, R. B. (2007). Forelimb stance and step cycle in Chasmosaurus irvinensis (Dinosauria: Neoceratopsia). Palaeontologia Electronica, 10(1), 5A http://palaeo-electronica. org/2007_1/step/index.html.

Thulborn, R. A. (1977). Relationships of the lower jurassic dinosaur Scelidosaurus harrisonii. Journal of Paleontology, 51, 725-739.

Thulborn, R. A. (1982). Speeds and gaits of dinosaurs. Palaeogeography, Palaeoclimatology, Palaeoecology, 38, 227-256.

Thulborn, R. A. (1989). The gaits of dinosaurs. In D. D. Gillette \& M. G. Lockley (Eds.), Dinosaur tracks and traces (pp. 39-50). Cambridge: Cambridge University Press.

Weishampel, D. B., Dodson, P., \& Osmólska, H. (Eds.). (2004). The dinosauria (2nd ed.). Berkeley: University of California Press. 
Weishampel, D. B., Jianu, C.-M., Csiki, Z., \& Norman, D. B. (2003). Osteology and phylogeny of Zalmoxes (n.g.), an unusual euornithopod dinosaur from the latest Cretaceous of Romania. Journal of Systematic Palaeontology, 1, 65-123.

Weishampel, D. B., \& Norman, D. B. (1989). Vertebrate herbivory in the Mesozoic; jaws, plants and evolutionary metrics. Geological Society of America Special Paper, 238, 87-100.

Wilkinson, D., \& Ruxton, G. D. (2013). High C/N ratio (not low energy content) of vegetation may have driven gigantism in sauropod dinosaurs and perhaps omnivory and/or endothermy in their juveniles. Functional Ecology, 27, 131-135.

Wilson, J. A., \& Carrano, M. T. (1999). Titanosaurs and the origin of "wide-gauge" trackways: a biomechanical and systematic perspective on sauropod locomotion. Paleobiology, 25, 252-267.

Yates, A. M., Bonnan, M. F., Neveling, J., Chinsamy, A., \& Blackbeard, M. G. (2010). A new transitional sauropodomorph dinosaur from the Early Jurassic of South Africa and the evolution of sauropod feeding and quadrupedalism. Proceedings of the Royal Society B, 277, 787-794.

Yates, A. M., \& Kitching, J. W. (2003). The earliest known sauropod dinosaur and the first steps toward sauropod locomotion. Proceedings of the Royal Society B, 270, 1753-1758.

Zanno, L. E., \& Makovicky, P. J. (2011). Herbivorous ecomorphology and specialization patterns in theropod dinosaur evolution. Proceedings of the National academy of Sciences of the United States of America, 108, 232-237.

Zhao, Q., Benton, M. J., Sullivan, C., Sander, P. M., \& Xu, X. (2013). Histology and postural change during the growth of the ceratopsian dinosaur Psittacosaurus lujiatunensis. Nature Communications, 4, 2079. https://doi.org/10.1038/ncomms3079. 